\title{
Assessing the acceptability of household textiles and apparels designed through foreign art motifs
}

\section{ADITI VISHNOI AND JYOTSNA SINGH}

Received: 08.09.2014; Accepted: 23.11.2014

See end of the paper for authors' affiliations

\section{ADITI VISHNOI}

Teerthanker Mahaveer

University, MORADABAD (U.P.)

INDIA
ABSTRACT : Human beings have always had a profound passion for decoration. Throughout history, art has served as both a means of decoration and individual expression and also act as a vehicle for the expression or communication of emotions and ideas. It is perceived through the eyes, but appreciated by the spirit. Its sole purpose is to stimulate the feeling of joy and peace. Modern India has a steep orientation towards western culture and fashion. Though it is dominating few million Indian women, still many of them stay with Indian culture by choosing style variation in their dressing sense. The study was undertaken by the researcher in designing sarees by using African art motifs in Indian traditional costume and Chinese motifs for designing kurties and Japanese motifs for designing home furnishing and handicraft items. The objectives for this study were to collect various ancient images of African, Chinese and Japanese arts, retrieve the motifs, designed household textiles and apparels with selected motifs and to analyze the aesthetic appeal of designed household textiles and apparels. It was concluded from the study that these arts are a successful innovation with reference to motifs, placement of motifs and colour combination. Thus, we can reach the height of fashion even by keeping out feet on traditional ground.

KEY WORDS: African art, Chinese and Japanese art, Motif, Textile, Apparel

- HOW TO CITE THIS PAPER : Vishnoi, Aditi and Singh, Jyotsna (2014). Assessing the acceptability of household textiles and apparels designed through foreign art motifs. Asian J. Home Sci., 9 (2) : 644-649. 